\title{
Gómez-López-Hernández syndrome
}

INSERM

\section{Source}

INSERM. (1999). Orphanet: an online rare disease and orphan drug data base. GómezLópez-Hernández syndrome. ORPHA:1532

Lopez-Hernandez syndrome, which may be classified among the neurocutaneous syndromes, associates abnormalities of the cerebellum (rhombencephalosynapsis), cranial nerves (trigeminal anesthesia), and scalp (alopecia). It has been reported in 11 individuals so far. Other features observed in patients were craniosynostosis, midfacial hypoplasia, bilateral corneal opacities, low-set ears, short stature, moderate intellectual impairment and ataxia. Hyperactivity, depression, self-injurious behaviour and bipolar disorder have also been reported. 